\title{
The year that was
}

\author{
The impacts of climate change were again increasingly apparent and the future was emphasized in the IPCC \\ Special Report, yet political change is still lagging.
}

\begin{abstract}
s 2018 comes to a close, it seems appropriate to reflect back on the year and the key events. At the time of writing, California is burning for the second time, with a spate of fires across the state in the middle of the summer (mid-July to August), and new flare ups in November. Over 1.6 million acres have burnt and the fires are the most destructive the state has seen. Further north, British Columbia, Canada, has had back-to-back record wildfire years, with 3.2 million acres of land burnt in 2018, the more destructive year (https://go.nature. com/2BgnieM). In our November 2017 editorial (Nat. Clim. Change 7, 755; 2017) we reflected on the 2017 wildfire season and questioned if it was a sign of things to come. This year has only reinforced those concerns.

Further to this, even Scandinavia was affected, a rare event, with fires breaking out in Finland, Russia, Norway and
\end{abstract}

Sweden - where over 25,000 acres were burnt (https://go.nature.com/2Kem9Ht).

Australia suffered a severe winter drought, described by some as the worst drought in living history (https://go.nature. com/2A2EEdx), with the entire state of New South Wales, an area responsible for around one-quarter of agricultural output by value, declared to be in drought (https://go.nature.com/2AeNJQD). Although there was some welcome rainfall over the austral spring, with a moderate El Niño predicted, it does not seem that there will be sufficient rain to help the region recover fully.

The release of the awaited IPCC Special Report on $1.5^{\circ} \mathrm{C}$ global warming (http:// www.ipcc.ch/report/sr15/) provided a timeline for emissions reductions, with clear statements on the difference in impacts between a 1.5 and $2{ }^{\circ} \mathrm{C}$ world. Warming is already at $1{ }^{\circ} \mathrm{C}$ globally, and to keep $1.5^{\circ} \mathrm{C}$ in sight, emissions need to be reduced by $\sim 45 \%$ of 2010 levels by 2030 - creating headline statements that there are 12 years left to halt climate change. Climate change is here now, as seen by the impacts emerging; that timeline provides an opportunity to limit further impacts.

Politically, the Brazilian elections saw Jair Bolsonaro installed as president - a right-wing politician who campaigned on an anti-environment agenda (Nature 563, 5-6; 2018). Changes in Brazilian policies, including the abandonment of those on deforestation control and land use, could have significant implications for mitigation and climate targets (Nat. Clim. Change 8, 695-698; 2018), just when we collectively need to be increasing ambition and facing the challenge of mitigation as the impacts become more apparent.

Published online: 29 November 2018 https://doi.org/10.1038/s41558-018-0369-5

\section{Saying thanks}

Nature Climate Change will now ask reviewers if they can be named on the published paper they reviewed.

$\int \mathrm{p}$ eer review is an essential part of the publication process, which through scrutiny of submitted articles strives to minimize errors and improve papers. The system of peer review has been generally consistent at Nature Research over recent decades: single blind, where the reviewers are anonymous to the authors.

This changed from June 2013, when we and Nature Geoscience offered authors the choice of their paper being considered under double-blind peer review, that is, where authors are unknown to the reviewers (Nat. Clim. Change 3, 525; 2013). Although there was relatively low uptake, this was recognized as a good service and the offer has been expanded across the Nature Research titles; it remains an author choice.

In another initiative, our sister journal Nature Communications has offered the publication of peer review reports since January 2016 (Nat. Commun. 6, 10277; 2015). The publication of reports and author rebuttals allows greater transparency of the review process and the information on which the editors base their decisions. The data for the first year of the initiative show a high level of uptake, particularly in ecology and evolution and the earth sciences (there is no data for social sciences), with over $70 \%$ author opt in. This compares to an average of $60 \%$ across all natural sciences at the journal (Nat. Commun. 7 , 13626; 2016).

These two initiatives offer changes predominantly on the author side of peer review, but what about the reviewers? Reviewers put in countless hours, with little recognition of these efforts. At Nature Research, reviewers are able to download a report of their referee activity across all journals in the family. This report can be accessed through your account on any of the journals submission pages, by accessing your 'My Nature Research' account and clicking on the manuscript tab.

In the coming weeks, Nature Climate Change will begin asking reviewers if they wish to be acknowledged for their contribution to the peer review process. This follows on from a trial at Nature that began in March 2016, in which if reviewer consent is obtained at the time the manuscript is accepted, reviewer names are included with thanks in the published paper. In the first 18 months $\sim 50 \%$ of reviewers consented (Nature 549, 431; 2017). If reviewers consent, we will include those names with thanks in the published paper, as well as a general thanks to those who choose to remain anonymous.

We recognize that this is one small step towards recognition of the many hours put in by reviewers, and will continue to discuss other initiatives - do get in touch with comments and suggestions. We would also like to take this opportunity to again thank all our reviewers for their efforts.

Published online: 29 November 2018 https://doi.org/10.1038/s41558-018-0366-8 